\title{
DNA MICROARRAY TECHNOLOGY AND BIOINFORMATIC WEB SERVICES
}

\author{
PAYAM BEHZADI ${ }^{*}$ and REZA RANJBAR ${ }^{2}$ \\ ${ }^{1}$ Department of Microbiology, College of Basic Sciences, Shahr-e-Qods Branch, Islamic \\ Azad University, Tehran, Iran \\ ${ }^{2}$ Molecular Biology Research Center, Systems Biology and Poisonings Institute, \\ Baqiyatallah University of Medical Sciences, Tehran, Iran
}

(Received: 7 February 2018; accepted: 7 April 2018)

\begin{abstract}
The pan-genomic microarray technique is used for environmental and/or clinical studies. Although microarray is an accurate and sharp diagnostic tool, the expertized bioinformaticians were able to minimize the outcome biases and maximize the flexibility and accuracy of the technique. The knowledge of bioinformatics plays a key role in association with probe designing and the utilization of correct probe sets and platforms. This technique is divided into two parts as dry lab (in silico studies) and wet lab (in vitro studies). Each part covers the other and are known as complementary divisions. In the case of microarray probe designing, a wide range of software, tools, and databases are necessary. Obviously, the application of right databases, software, and tools decreases the probable biases in the outcomes. Due to the importance of suitable probe designing, this article has focused its look onto a variety of online/ offline databases, software, and tools.
\end{abstract} database

Keywords: microarray, computational molecular biology, bioinformatics,

\section{Introduction}

Although there are several diagnostic tools that can be applied for detection and identification of microbial causative agents of infectious diseases, microarray technology is the latest production of a harmonic multidisciplinary orchestra; an influent combination of scientific disciplines and intradisciplines with an effective and powerful outcome. Indeed, this tool is based on Biochemistry, Bioinformatics, Biology, Biophysics, Chemistry, Computer, Genetics, Mathematics, and Molecular biology, which make it sharp, accurate, and reliable [1-3]. Depending on target biomolecules, microarray can be classified into three separate techniques: DNA,

*Corresponding author; E-mail: behzadipayam@yahoo.com 
RNA, and protein microarrays. However, there are much more target biomolecules, biopolymers, and biological structures [carbohydrates and peptides (polymers), cells, tissues, and a vast range of small molecules] [4-9]. The basis of microarray technology goes back to some decades ago. Dot blotting technique as a simple molecular tool has been led to an occurrence of the advanced pangenomic technology of microarray. Edwin Mellor Southern invented two important nucleic acid-based methods. In 1973, he invented the valuable technique of southern blot, which resulted in the invaluable technique of microarray. Therefore, in 1985, microarray was funded and has progressed by the time. Because of the establishment of a diversity of online and offline software, tools, and databases, the molecular nucleic acid-based technologies have had a significant progression in the recent four decades [10-12]. There is a wide range of diagnostic tools with particular properties. Among different types of lab tools and technologies, nucleic acid-based techniques seem to be reliable and useful. For example, when the number of samples is limited, polymerase chain reaction (PCR) is the proper approach as a well-known molecular diagnostics, but in the case of huge samples, PCR is not recommended because it will be time-consuming and expensive. Therefore, the application of DNA microarray is a good choice, when there is an abundance of samples [13-16]. Therefore, here, it will be discussed about the DNA microarray characteristics and a variety of common online/offline databases, software, and tools.

\section{DNA Microarray Characteristics}

DNA microarray - a lab-on-chip diagnostic technique - is a miniaturized technology, which can be applied for different clinical and medical environmental specimen recognitions. This automatic and robotic fluorescent nucleic acid-based technology is divided into two parts as dry lab and wet lab. The term dry lab denotes the bioinformatic portion of the technology, whereas the wet lab is related to molecular biology practical experiments. Moreover, this technique resembles a puzzle that must be completed by related puzzle pieces. Probe designing, probe printing, target biomolecule labeling, hybridization, and scanning are the intensive pieces of the microarray technology puzzle. The probe designing section is known as an in silico procedure that should be performed in dry lab, whereas the wet lab section of the technology (probe spotting, target labeling, hybridization, and scanning) involves the in vitro portion. The unique characteristics of microarray includes the immobilization of specific designed probes as anchored sequences on a solid and coated chip to analyze a genome, a proteome, or a transcriptome among a huge number of samples and specimens [1, 3, 4, 16-23]. 
Dry lab section

Probe designing. Although microarray technology is a multisectional diagnostic tool, the accuracy of final results relies on the quality of employed bioinformatics tools, software, and databases. Appropriate designed microarray probes guarantee the quality of the outcome and the final results. Therefore, an unsuitable microarray probe designing may lead to incredible biases. In other words, the in silico section of the technique determinates the accuracy, sensitivity, specificity, and flexibility of the microarray final outcomes. In addition to proper probe designing, the type of the probe must be compatible with the coating material of chip. Therefore, there is a mass of technical details in association with bioinformatics tools, which must be considered for a successful diagnosis [16, 23-26]. The type of the target molecules, microarray platform, and designed probes determine the kind of coating material of the chip. Besides, the microarray platform and the in vitro (wet lab) section of the technique affect the methodology of the in silico section of probe designing. The section of probe designing can be done with the help of different public sequence databases. Indeed, for designing sensitive and specific microarray probes, it is important to know the correct sequences of the targets. Hence, the sequences of target molecules can be obtained from specific databases. The DNA Data Bank of Japan (DDBJ) (http://www.ddbj.nig.ac.jp/), the European Nucleotide Archive (ENA) (www.ebi.ac.uk/ena) supported by European Molecular Biology - The European Bioinformatics Institute (EMBLEBI) (http://www.ebi.ac.uk/), and the National Center for Biotechnology Information (NCBI) (http://www.ncbi.nlm.nih.gov/) are recognized as three important sequence databases that can be used for free. Simultaneously, the International Nucleotide Sequence Database Collaboration (http://www.insdc.org/) acts as a multifunctional global coordinator database, which covers these three aforementioned databases [2, 16, 24, 27-33]. In parallel with general sequence databases of DDBJ, ENA, and NCBI, there are some specific resources that cover limited groups of organisms. These web services including The SEED (http://pubseed. theseed.org/) (for prokaryotes including archaea and bacteria), the Rapid Annotation of microbial genomes using Subsystems Technology (http://rast.nmpdr.org/) (for prokaryotes including archaea and bacteria), the microbial genome database (http://mbgd.genome.ad.jp/), the Comprehensive Microbial Resource (http://cmr. jcvi.org/) (for prokaryotes including archaea and bacteria), the Pathosystems Resource Integration Center (https://www.patricbrc.org/) (for prokaryotes including bacteria), the Virus Pathogen Database and Analysis Resource (www. ViPRbrc.org), the Human Immunodeficiency Virus sequence database (http:// www.hiv.lanl.gov), and the Influenza Research Database (www.fludb.org) may lead to have an easier process of designing high-quality microarray probes. 
Interestingly, the Atlas of Biological Databases and Tools (http://bis.zju.edu.cn/ $\mathrm{DaTo} /$ ) is an extraordinary database, which provides its users to have a precise evaluation of bioinformatics tools and databases [34-39]. It is absolutely important to employ powerful web services and skillful bioinformaticians for designing sensitive, specific, sharp, and effective microarray probes. It is clear that inappropriate probe designing may lead to huge misdiagnoses and biases.

In silico process. Our final goal in DNA microarray technology leads us to recruit proper online and/or offline tools, software, databases, and other web services. Therefore, dry lab section of microarray technique is known as a critical portion of this technology to have a sharp, rapid, effective, accurate, sensitive, and specific diagnosis. In recent years, there is a diversity of general and specific databases, abundance servers, tools, and software, which can be employed to design best types of probes with high quality, reliability, sensitivity, and specificity. As mentioned before, the quality of microarray probes is the most important part in microarray technology; there are several thousand probes that must act as unique strands matching with their specific target sequences. To design proper microarray probes, there is a need for a powerful and effective online and/or offline web servers, tools, and software. Some tools, such as Basic Local Alignment Search Tool (https://blast.ncbi.nlm.nih.gov/Blast.cgi), are important for aligning selected sequences. Furthermore, servers like GView (https://server.gview.ca/) and PanSeq (https://lfz.corefacility.ca/panseq/) are suitable tools for analyzing and visualizing the related sequences. In the following steps, the unique sequences will be processed by probe designer software. Table I shows a number of accessible DNA microarray probe designing software [2, 3, 16, 19, 23, 25, 26, 37, 40-65].

Finally, the designed probes must be rechecked by online tools for their biophysical and physicochemical properties. OligoAnalyzer (http://eu.idtdna.com/ calc/analyzer) is an appropriate free online tool that can be used for final evaluation $[16,19,23,25,26,66]$.

\section{Wet lab section}

Probe spotting. The process is performed with the help of robotic spotters. The immobilization of probes is achieved on the surface of different types of chips. There are three groups of array platforms, including microwell, micropillar, and glass. For the most, glass slides are used as proper solid surfaces that are coated by different active materials to increase the level of probe efficacy. In addition, the types of designed probes and target molecules determine the coating material of the glass chips. There are several companies that manufacture glass slides with a wide range of slide coats and covers such as epoxy (inorganic structures), $\mathrm{CHO}$ (oxide component), hydrogel (hydrophilic polymers), gold (metals), etc. An appropriate 


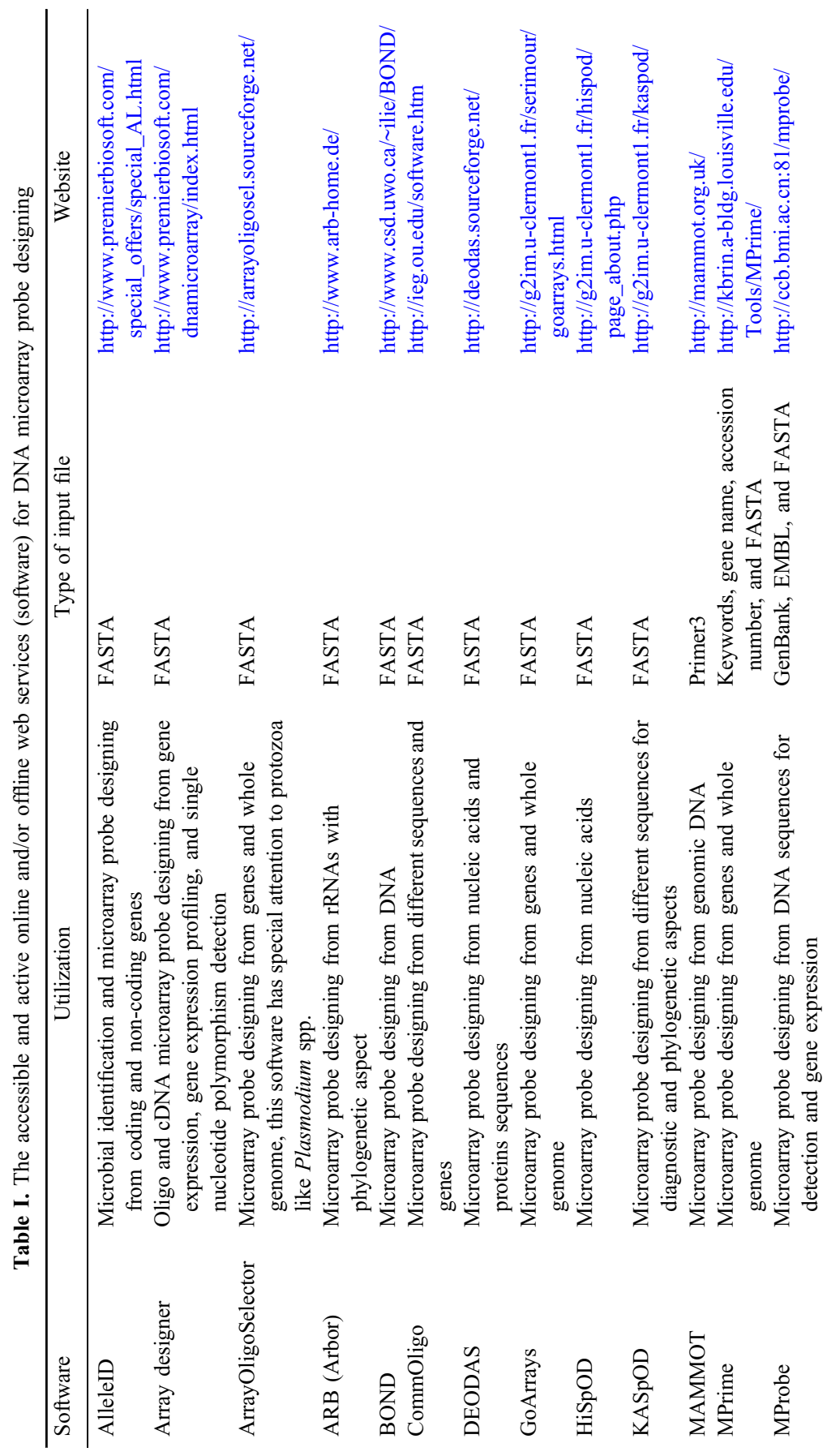




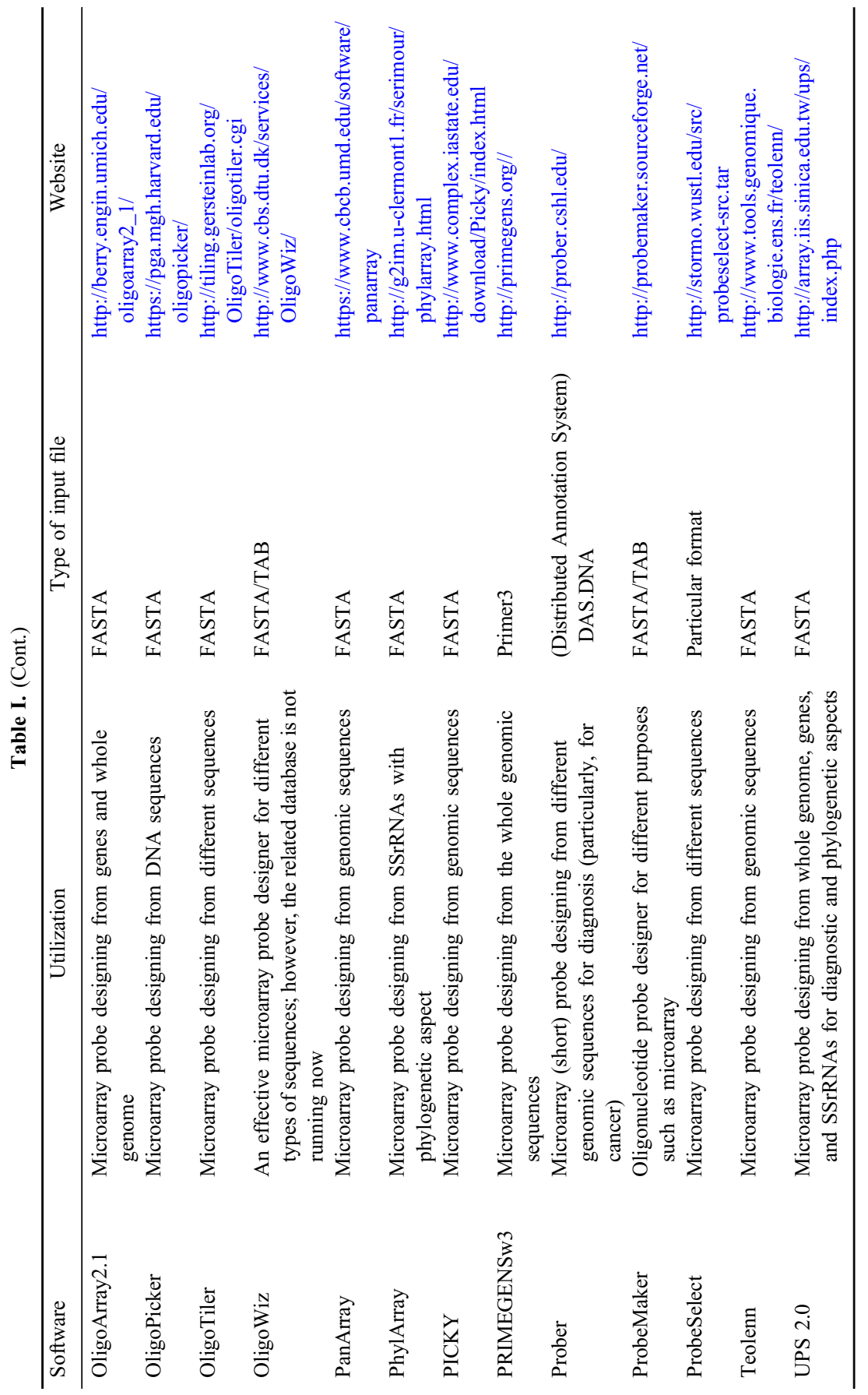


coating material guarantees an effective probe immobilization process. Schott and PerkinElmer are the two well-known companies that contribute in manufacturing different types of microarray glass slides. The epoxy-coated glass slides are recognized as the most applicable platforms for a diversity of probes. The immobilized probes on the chips are affected by electrostatic bonds and forces; thus, the use of linkers (e.g., alkanes containing 6-12 carbon atoms, 5-15 meric adenine or thymidine) is recommended to the anchored end of the probes. The probe spacers supply stable bonds between probes and the surface of a chip. Altogether, the quality of the chip surface has a deep effect on results [23, 37, 67, 68].

Spotter and microarray chip fabrication. In DNA microarray technology depending on the type of spotter, the diameters of the spotted samples must be $\geq 200 \mu \mathrm{m}$. Therefore, knowing the type of the spotter guarantees the favor pattern on the array surface. Soft lithography, photolithography, and robotic spotting are general printing systems that are applied for patterning sample spots on microchips. The utilization of each type of spotter is directly related to the type of probe molecules. Probe spotters are programmed by a vast range of commercial software [2, 67-69].

Target-labeling process. The target molecule should be labeled by fluorescent dyes. Indeed, the result can be illustrated by visualizing molecular interactions. Fluorescein (e.g., Singapore green) and cyanine (e.g., Cy3 and Cy5) dyes are wellknown labeling tags. The application of one or two different types of dyes is associated with the final goal. For detection and identification of microorganisms, it can be covered by a single color (a one-channel microarray), but for detection and identification of diseases like cancers, a two-channel microarray is needed [23, 68, 70-72].

Hybridization process. The process of hybridization in which labeled target sequences must be linked to their complementary immobilized probe sequences is an important section with huge concern. The length of targets and probes has a direct effect on the process of hybridization. The long sequences may provide some structures that prevent hybridizing process. This may lead to false-negative/positive results and vice versa. In other words, too short sequences may lead to falsepositive outcomes. There is a diversity of hybridization protocols for nucleic acids, which can be done automatically or manually. In contrast to manual hybridization, the robotic hybridization is recommended. Obviously, there are different types of hybridization apparatus with their particular software [23, 68, 72, 73].

Scanning process. The process of scanning is achieved by scanner. This stage completely depends on probe designing, probe spotting, target labeling, and hybridization sections. Any problem in these sections leads to huge biases and incorrect analyses. The outcomes including fluorescent emission from printed spots are recorded by camera for final analyses and interpretations [2, 16, 19, 31, 68, 72, 73]. 


\section{Conclusions}

DNA microarray technology as an advanced pan-genomic technique is completely related to bioinformatics. By the use of appropriate software, tools, and databases, we are able to design qualified DNA microarray probes. Therefore, the progression of Internet facilities including online and/or offline web services has depth and direct effect on the quality of final microarray outcomes. DNA microarray like other pan-genomic and molecular techniques has some advantages and disadvantages. But in toto, this technology is an accurate, reliable, sensitive, specific, and cost effective one, which can be helpful when the number of specimens is too high.

\section{Acknowledgements}

The corresponding author of this paper appreciates Prof. Wuju Li's sincere collaboration for introducing the web page of Mprobe 2.0: Computer-aided probe design for oligonucleotide microarrays (http://ccb.bmi.ac.cn:81/mprobe/).

\section{Conflict of Interest}

The authors declare no conflict of interest.

\section{References}

1. Behzadi, P., Behzadi, E., Ranjbar, R.: The application of microarray in medicine. ORL 24, 24-26 (2014).

2. Behzadi, P., Behzadi, E., Ranjbar, R.: Microarray probe set: Biology, bioinformatics and biophysics. Alban Med J 2, 78-83 (2015).

3. Behzadi, P., Behzadi, E., Alavian, S. M.: DNA microarray technology in HBV genotyping. Minerva Med 108, 473-476 (2017).

4. Li, P., Sedighi, A., Wang, L. (eds): Microarray Technology. Methods in Molecular Biology. Humana Press, New York, 2016, pp. 3-10.

5. Behzadi, P., Behzadi, E., Ranjbar, R.: IL-12 family cytokines: General characteristics, pathogenic microorganisms, receptors, and signalling pathways. Acta Microbiol Immunol Hung 63, 1-26 (2016).

6. Behzadi, E., Behzadi, P.: The role of toll-like receptors (TLRs) in urinary tract infections (UTIs). Cent Eur J Urol 69, 404-410 (2016).

7. Behzadi, P., Behzadi, E.: Uropathogenic Escherichia coli: An ideal resource for DNA microarray probe designing. In Rojas, I., Ortuño, F., (eds): International Conference on 
Bioinformatics and Biomedical Engineering (IWBBIO 2017). Springer, Granada, 2017, pp. 12-19.

8. Ranjbar, R., Behzadi, P., Farshad, S.: Advances in diagnosis and treatment of Helicobacter pylori infection. Acta Microbiol Immunol Hung 64, 273-292 (2017).

9. Fahmideh, L., Kord, H., Shiri, Y.: Importance of microarray technology and its applications. J Curr Res Sci 4, 25 (2016).

10. Heller, M. J.: DNA microarray technology: Devices, systems, and applications. Annu Rev Biomed Eng 4, 129-153 (2002).

11. Tofano, D., Wiechers, I. R., Cook-Deegan, R.: Edwin Southern, DNA blotting, and microarray technology: A case study of the shifting role of patents in academic molecular biology. Genomics Soc Policy 2, 1-12 (2006).

12. Tang, Y.-W., Stratton, C. W.: Advanced Techniques in Diagnostic Microbiology. Springer, New York, 2006.

13. Behzadi, E., Behzadi, P., Sirmatel, F.: Identification of 30-kDa heat shock protein gene in Trichophyton rubrum. Mycoses 52, 234-238 (2009).

14. Ranjbar, R., Tabatabaee, A., Behzadi, P., Kheiri, R.: Enterobacterial repetitive intergenic consensus polymerase chain reaction (ERIC-PCR) genotyping of Escherichia coli strains isolated from different animal stool specimens. Iranian J Pathol 12, 25-34 (2017).

15. Ranjbar, R., Bolandian, M., Behzadi, P.: Virulotyping of Shigella spp. isolated from pediatric patients in Tehran, Iran. Acta Microbiol Immunol Hung 64, 71-80 (2017).

16. Ranjbar, R., Behzadi, P., Mammina, C.: Respiratory tularemia: Francisella tularensis and microarray probe designing. Open Microbiol J 10, 176-182 (2016).

17. Behzadi, P., Najafi, A., Behzadi, E., Ranjbar, R.: Detection and identification of clinical pathogenic fungi by DNA microarray. Infectioro 35, 6-10 (2013).

18. Behzadi, P., Ranjbar, R., Alavian, S. M.: Nucleic acid-based approaches for detection of viral hepatitis. Jundishapur J Microbiol 8, e17449 (2014).

19. Behzadi, P., Ranjbar, R.: Microarray long oligo probe designing for bacteria: An in silico pan-genomic research. Alban Med J 2, 5-11 (2016).

20. Lamberti, A., Sanges, C., Migliaccio, N., De Stefano, L., Rea, I., Orabona, E., Scala, G., Rendina, I., Arcari, P.: Silicon-based technology for ligand-receptor molecular identification. J At Mol Opt Phys 2012, 948390 (2012).

21. Zvara, Á., Kitajka, K., Faragó, N., Puskás, L.: Microarray technology. Acta Biol Szegediensis 59, 51-67 (2015).

22. Ranjbar, R., Karami, A., Farshad, S., Giammanco, G. M., Mammina, C.: Typing methods used in the molecular epidemiology of microbial pathogens: A how-to guide. New Microbiol 37, 1-15 (2014).

23. Ranjbar, R., Behzadi, P., Najafi, A., Roudi, R.: DNA microarray for rapid detection and identification of food and water borne bacteria: From dry to wet lab. Open Microbiol J 11, 330-338 (2017).

24. López-Campos, G., Martínez-Suárez, J. V., Aguado-Urda, M., López-Alonso, V.: Microarray Detection and Characterization of Bacterial Foodborne Pathogens. Springer Science \& Business Media, Boston, 2012, pp. 33-47, 49-52.

25. Jahandeh, N., Ranjbar, R., Behzadi, P., Behzadi, E.: Uropathogenic Escherichia coli virulence genes: Invaluable approaches for designing DNA microarray probes. Cent Eur J Urol 68, 452-458 (2015). 
26. Behzadi, P., Najafi, A., Behzadi, E., Ranjbar, R.: Microarray long oligo probe designing for Escherichia coli: An in-silico DNA marker extraction. Cent Eur J Urol 69, 105-111 (2016).

27. Mashima, J., Kodama, Y., Fujisawa, T., Katayama, T., Okuda, Y., Kaminuma, E., Ogasawara, O., Okubo, K., Nakamura, Y., Takagi, T.: DNA data bank of Japan. Nucleic Acids Res 45, D25-D31 (2016).

28. Cook, C. E., Bergman, M. T., Finn, R. D., Cochrane, G., Birney, E., Apweiler, R.: The European Bioinformatics Institute in 2016: Data growth and integration. Nucleic Acids Res 44, D20-D26 (2016).

29. NCBI Resource Coordinators: Database resources of the national center for biotechnology information. Nucleic Acids Res 45, D12-D17 (2017).

30. Behzadi, P., Behzadi, E., Ranjbar, R.: Basic Modern Molecular Biology, $1^{\text {st }}$ Edition. Persian Science \& Research Publisher, Tehran, 2014, pp. 1-4.

31. Behzadi, P., Behzadi, E., Ranjbar, R.: Microarray data analysis. Alban Med J 4, 84-90 (2014).

32. Cochrane, G., Karsch-Mizrachi, I., Takagi, T., Collaboration, I. N. S. D.: The International Nucleotide Sequence Database Collaboration. Nucleic Acids Res 44, D48-D50 (2016).

33. Ventimiglia, G., Alessi, E., Petralia, S.: A bridge-like solution for universal microarray applications. Sens Actuators B Chem 232, 102-106 (2016).

34. Overbeek, R., Olson, R., Pusch, G. D., Olsen, G. J., Davis, J. J., Disz, T., Edwards, R. A., Gerdes, S., Parrello, B., Shukla, M.: The SEED and the rapid annotation of microbial genomes using subsystems technology (RAST). Nucleic Acids Res 42, D206-D214 (2014).

35. Wattam, A. R., Davis, J. J., Assaf, R., Boisvert, S., Brettin, T., Bun, C., Conrad, N., Dietrich, E. M., Disz, T., Gabbard, J. L.: Improvements to PATRIC, the all-bacterial bioinformatics database and analysis resource center. Nucleic Acids Res 45, D535-D542 (2017).

36. Pickett, B. E., Sadat, E. L., Zhang, Y., Noronha, J. M., Squires, R. B., Hunt, V., Liu, M., Kumar, S., Zaremba, S., Gu, Z.: ViPR: An open bioinformatics database and analysis resource for virology research. Nucleic Acids Res 40, D593-D598 (2012).

37. Li, Q., Zhou, Y., Jiao, Y., Zhang, Z., Bai, L., Tong, L., Yang, X., Sommer, B., Hofestädt, R., Chen, M.: DaTo: An atlas of biological databases and tools. J Integr Bioinformatics 13, 297 (2016).

38. Uchiyama, I., Higuchi, T., Kawai, M.: MBGD update 2010: Toward a comprehensive resource for exploring microbial genome diversity. Nucleic Acids Res 38, D361-D365 (2010).

39. Davidsen, T., Beck, E., Ganapathy, A., Montgomery, R., Zafar, N., Yang, Q., Madupu, R., Goetz, P., Galinsky, K., White, O.: The comprehensive microbial resource. Nucleic Acids Res 38, D340-D345 (2009).

40. Lemoine, S., Combes, F., Le Crom, S.: An evaluation of custom microarray applications: The oligonucleotide design challenge. Nucleic Acids Res 37, 1726-1739 (2009).

41. Apte, A., Singh, S.: AlleleID: A pathogen detection and identification system. PCR Primer Des 329-345 (2007).

42. Zhu, J., Bozdech, Z., DeRisi, J.: ArrayOligoSelector. (2003). Available at http://arrayoligosel. sourceforge.net 
43. Ludwig, W., Strunk, O., Westram, R., Richter, L., Meier, H., Buchner, A., Lai, T., Steppi, S., Jobb, G., Förster, W.: ARB: A software environment for sequence data. Nucleic Acids Res 32, 1363-1371 (2004).

44. Westram, R., Bader, K., Prüsse, E., Kumar, Y., Meier, H., Glöckner, F. O., Ludwig, W.: ARB: A software environment for sequence data. In de Bruijn, F. J. (ed): Handbook of Molecular Microbial Ecology I: Metagenomics and Complementary Approaches. John Wiley \& Sons, Inc., Hoboken, New Jersey, 2011, pp. 399-406.

45. Ilie, L., Mohamadi, H., Golding, G. B., Smyth, W. F.: BOND: Basic oligonucleotide design. BMC Bioinformatics 14, 69 (2013).

46. Li, X., He, Z., Zhou, J.: Selection of optimal oligonucleotide probes for microarrays using multiple criteria, global alignment and parameter estimation. Nucleic Acids Res 33, 6114-6123 (2005).

47. Dugat-Bony, E., Missaoui, M., Peyretaillade, E., Biderre-Petit, C., Bouzid, O., Gouinaud, C., Hill, D., Peyret, P.: HiSpOD: Probe design for functional DNA microarrays. Bioinformatics 27, 641-648 (2011).

48. Rimour, S., Hill, D., Militon, C., Peyret, P.: GoArrays: Highly dynamic and efficient microarray probe design. Bioinformatics 21, 1094-1103 (2005).

49. Parisot, N., Denonfoux, J., Dugat-Bony, E., Peyret, P., Peyretaillade, E.: KASpOD - A web service for highly specific and explorative oligonucleotide design. Bioinformatics 28, 3161-3162 (2012).

50. Ryder, E., Jackson, R., Ferguson-Smith, A., Russell, S.: MAMMOT - A set of tools for the design, management and visualization of genomic tiling arrays. Bioinformatics 22, 883-884 (2006).

51. Rouchka, E. C., Khalyfa, A., Cooper, N. G.: MPrime: Efficient large scale multiple primer and oligonucleotide design for customized gene microarrays. BMC Bioinformatics 6, 175 (2005).

52. Li, W., Huang, J., Fan, M., Wang, S.: MProbe: Computer aided probe design for oligonucleotide microarrays. Appl Bioinformatics 1, 163-166 (2002).

53. Rouillard, J.-M., Herbert, C. J., Zuker, M.: OligoArray: Genome-scale oligonucleotide design for microarrays. Bioinformatics 18, 486-487 (2002).

54. Wang, X., Seed, B.: Selection of oligonucleotide probes for protein coding sequences. Bioinformatics 19, 796-802 (2003).

55. Jourdren, L., Duclos, A., Brion, C., Portnoy, T., Mathis, H., Margeot, A., Le Crom, S.: Teolenn: An efficient and customizable workflow to design high-quality probes for microarray experiments. Nucleic Acids Res 38, e117 (2010).

56. Wernersson, R., Nielsen, H. B.: OligoWiz 2.0 - Integrating sequence feature annotation into the design of microarray probes. Nucleic Acids Res 33, W611-W615 (2005).

57. Phillippy, A. M., Deng, X., Zhang, W., Salzberg, S. L.: Efficient oligonucleotide probe selection for pan-genomic tiling arrays. BMC Bioinformatics 10, 293 (2009).

58. Militon, C., Rimour, S., Missaoui, M., Biderre, C., Barra, V., Hill, D., Moné, A., Gagne, G., Meier, H., Peyretaillade, E.: PhylArray: Phylogenetic probe design algorithm for microarray. Bioinformatics 23, 2550-2557 (2007).

59. Chou, H.-H.: Shared probe design and existing microarray reanalysis using PICKY. BMC Bioinformatics 11, 196 (2010). 
60. Kushwaha, G., Srivastava, G. P., Xu, D.: PRIMEGENSw3: A web-based tool for high-throughput primer and probe design. PCR Primer Des 181-199 (2015).

61. Navin, N., Grubor, V., Hicks, J., Leibu, E., Thomas, E., Troge, J., Riggs, M., Lundin, P., Månér, S., Sebat, J.: PROBER: Oligonucleotide FISH probe design software. Bioinformatics 22, 2437-2438 (2006).

62. Stenberg, J., Nilsson, M., Landegren, U.: ProbeMaker: An extensible framework for design of sets of oligonucleotide probes. BMC Bioinformatics 6, 229 (2005).

63. Hosur, R., Szak, S., Thai, A., Allaire, N., Bienkowska, J.: ProbeSelect: Selecting differentially expressed probes in transcriptional profile data. Bioinformatics 30, 574-575 (2013).

64. Chen, S.-H., Lo, C.-Z., Su, S.-Y., Kuo, B.-H., Hsiung, C. A., Lin, C.-Y.: UPS 2.0: Unique probe selector for probe design and oligonucleotide microarrays at the pangenomic/ genomic level. BMC Genomics 11, S6 (2010).

65. Behzadi, P.: Uropathogenic Escherichia coli and Fimbrial Adhesins Virulome. In Jarzembowski, T. (ed): Urinary Tract Infection - The Result of the Strength of the Pathogen, or the Weakness of the Host. InTech, Croatia, 2018, pp. 65-83.

66. Owczarzy, R., Tataurov, A. V., Wu, Y., Manthey, J. A., McQuisten, K. A., Almabrazi, H. G., Pedersen, K. F., Lin, Y., Garretson, J., McEntaggart, N. O.: IDT SciTools: A suite for analysis and design of nucleic acid oligomers. Nucleic Acids Res 36, W163-W169 (2008).

67. Lee, M.-Y.: Microarray Bioprinting Technology: Fundamentals and Practices. Springer, Cham, 2017, pp. 1-100.

68. Kostic, T., Butaye, P., Schrenzel, J.: Detection of Highly Dangerous Pathogens: Microarray Methods for BSL 3 and BSL 4 Agents. Wiley, Weinheim, 2009, pp. 1-10, 85-104.

69. Dufva, M.: Fabrication of high quality microarrays. Biomol Eng 22, 173-184 (2005).

70. Li, J., Yao, S. Q.: "Singapore Green": A new fluorescent dye for microarray and bioimaging applications. Org Lett 11, 405-408 (2008).

71. Uttamchandani, M., Yao, S. Q.: Small Molecule Microarrays: Methods and Protocols. Humana Press, New York, 2010, pp. 1-18.

72. Najafi, A., Ram, M., Ranjbar, R.: Microarray: Principles \& Applications, $1^{\text {st }}$ Edition. Persian Science \& Research Publisher, Tehran, 2012, pp. 13-39.

73. Matson, R. S.: Microarray Methods and Protocols. CRC Press, Boca Raton, 2009, pp. 1-11. 